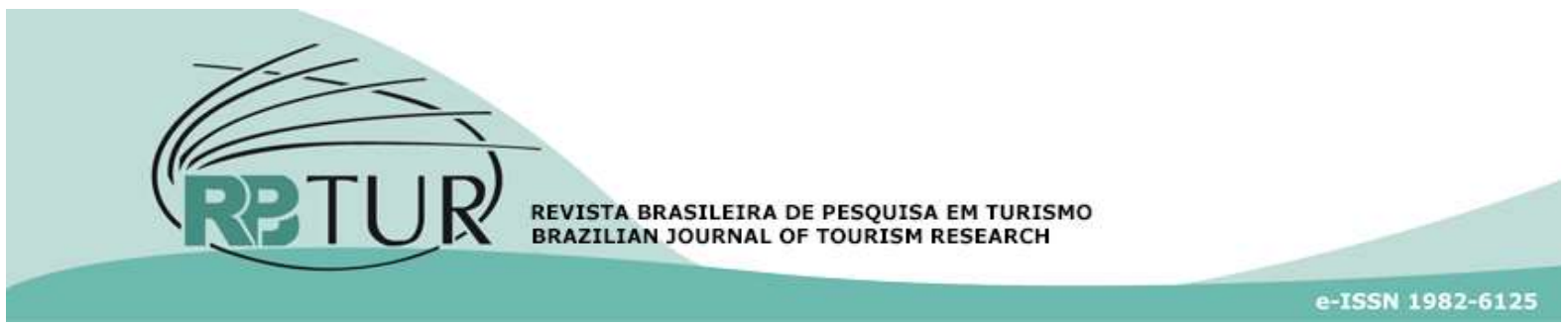

Artigo

DOI: http://dx.doi.org/10.7784/rbtur.v12i3.1437

\title{
Impactos da Volvo Ocean Race - Itajaí Stopover: análise pós- evento da percepção dos residentes da cidade de Itajaí (SC)
}

\author{
Impacts of Volvo Ocean Race - Itajaí Stopover: a post-event analysis \\ of the perception of the residents of the city of Itajaí (SC)
}

\section{Impactos de Volvo Ocean Race - Itajaí Stopover: un análisis post- evento de la percepción de los residentes de la ciudad de Itajaí (SC)}

\author{
Josy Vieira ${ }^{1}$ \\ Carlos Marcelo Ardigó 2 \\ Hans Peder Behling ${ }^{3}$
}

\begin{abstract}
${ }^{1}$ Universidade do Vale do Itajaí (UNIVALI), Balneário Camboriú, SC, Brasil. Contribuição: Atuou em todas as etapas da pesquisa, bem como da produção do manuscrito, incluindo a definição do problema de pesquisa e objetivos, desenvolvimento da proposição teórica, com a realização da revisão bibliográfica e construção da fundamentação teórica. A coleta e a análise de dados, bem como a elaboração de tabelas, dos cálculos e projeções também foram realizadas pela autora. A redação do manuscrito e a adequação do manuscrito às normas da RBTur foram atividades em que atuou diretamente.

2 Universidade do Vale do Itajaí (UNIVALI), Balneário Camboriú, SC, Brasil. Contribuição: O envolvimento no estudo se deu a partir da definição e delimitação do tema, do problema de pesquisa, bem como na definição dos objetivos. Na fase teórica, com a proposição e realização da revisão bibliográfica, as atividades realizadas foram de seleção da literatura a partir da aderência ao tema. Na construção do texto da fundamentação teórica, o papel foi principalmente de revisor, porém também atuando na construção propriamente dita. Atuou na escolha dos procedimentos metodológicos, tanto de delineamento do estudo, definição de instrumento, forma de coleta e de análise dos dados. Na apresentação dos dados por meio das tabelas, agiu no sentido de colaborar com a definição da melhor forma para uma apresentação objetiva. Cumpriu também tarefas de revisão crítica do manuscrito em todas as fases do processo de publicação.

${ }^{3}$ Universidade do Vale do Itajaí (UNIVALI), Itajaí, SC, Brasil. Contribuição: Atuou na colaboração de definição e delimitação do tema, do problema de pesquisa, bem como na definição dos objetivos. Na fundamentação teórica, colaborou como revisor. Atuou diretamente na concepção dos procedimentos metodológicos, quanto ao seu delineamento. Fez revisões sistemáticas nas análises dos dados, bem como cumpriu tarefas de revisão crítica do manuscrito em todas as fases. Contribuiu na adequação do manuscrito às normas da RBTur.
\end{abstract}

Artigo recebido em: 04/04/2018. Artigo aceito em: 21/08/2018.

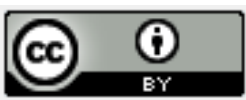


Resumo: A Volvo Ocean Race (VOR) é um megaevento mundial, com potencial para atrair público e investimentos para os diferentes países que o recebe, sendo ainda um importante atrativo relacionado ao turismo náutico. Passadas as edições de 2012/2013 e 2014/2015 e as vésperas de sediar uma das etapas da edição 2017/2108 este estudo procurou analisar a percepção dos residentes da cidade de Itajaí (SC), após a realização do Itajaí Stopover (recepção do evento na cidade), em relação aos impactos econômicos, socioculturais e ambientais gerados pela VOR. A metodologia aplicada seguiu um delineamento descritivo, com natureza dos dados predominantemente quantitativa e procedimento survey, aplicado a uma amostra não probabilística de 484 respondentes. Para a análise utilizou-se além da estatística descritiva também o teste ANOVA para identificação de diferenças de média entre perfis diferentes de residentes respondentes. Os resultados apontam que para a maioria dos residentes a VOR proporcionou impactos positivos, independentemente do nível de proximidade de suas residências da Vila da Regata do Itajaí Stopover. Grupos etários, de gênero, níveis de instrução e renda também tendem a perceber de maneira distinta para determinadas variáveis e dimensões analisadas.

Palavras-chave: Eventos Desportivos e Esportivos. Turismo Náutico. Impacto de Eventos. Residentes

Abstract: Volvo Ocean Race (VOR) is a worldwide mega event, with potential to attract public and investors to the different countries that host it, being an important attraction for nautical tourism. After 2012/2013 and 2014/2015 editions, and just about to host one of the 2017/2018 season events, this study aimed to analyze the perception of the residents of the city of Itajai (SC), after the Itajai Stopover (event reception in the city), relating to the economic, sociocultural and environmental impacts generated by VOR. The applied method followed a descriptive alignment, with data predominantly quantitative and survey procedure applied to a non-probabilistic sample of 484 cases. For the analysis, besides basic descriptive statistics, the ANOVA test was applied to identify average differences between the different respondent profiles. The results showed that for most residents, VOR had positive impacts, independently of the proximity level of their households to the Villa hosting the Itajai Stopover. Gender, age, instruction and income groups also tend to perceive distinctly the analyzed variables and dimensions.

Keywords: Sports and Sporting Events. Nautical Tourism. Event Impact. Residents.

Resumen: El Volvo Ocean Race (VOC) es un gran evento mundial con potencial para atraer público e inversores para los diferentes países que lo recibe, siendo además un importante atractivo relacionado al turismo náutico. Posterior a las ediciones de 2012/2013 y 2014/2015, y cerca de hospedar una de las etapas de la edición de 2017/2018, este estudio buscó analizar la percepción de los residentes de la ciudad de Itajaí (SC), luego de la realización del Itajaí Stopover (recepción del evento en la ciudad), en relación a los impactos económicos, socioculturales y ambientales originados por el VOR. La metodología aplicada siguió un delineamiento descriptivo, con la naturaleza de los dados predominantemente cuantitativa y procedimiento de encuestas, aplicado a una muestra no probabilística de 484 casos. Para su análisis se utilizó, además de la estadística descriptiva, también la prueba ANOVA para la identificación de diferencias de promedios entre los perfiles diferentes de residentes respondientes. Los resultados apuntan que para la mayoría de los residentes, el VOR proporcionó impactos positivos, independientemente del nivel de proximidad de sus residencias a la Vila da Regata del Itajaí Stopover. Grupos etarios, de genero, niveles de instrucción y de ingreso también tienden a notar de manera distinta las determinadas variables y dimensiones analizadas.

Palabras clave: Eventos Deportivos. Turismo Náutico. Impacto de Eventos. Residentes.

\section{INTRODUÇÃO}

No aspecto histórico, a atividade turística, da forma como atualmente é conhecida, pode ser considerada relativamente nova, pois sua intensificação se remete às úl- timas décadas, principalmente com o advento da globalização, tornando-se um dos maiores fenômenos do mercado e obtendo assim uma grande importância econômica (Barbosa, 2013). Nessa perspectiva econômica, trata-se de uma importante ferra- 
menta para o desenvolvimento local, impactando positivamente na geração de emprego e renda (Santos \& Wanderley, 2009, Barros \& Granero, 2010).

Cientes dessa contribuição, as três instâncias governamentais (municipal, estadual e federal) vêm alertando para a necessidade de investimentos nesse setor, destinando políticas específicas para ampliar essa atividade econômica (Barbosa, 2005). Entretanto, para que de fato seja efetiva a atividade no que concerne a contribuição para o desenvolvimento de uma região, é necessário planejamento em face da vocação local (Zucco, Quadros, Schmitt \& Fiuza, 2017), ou seja, a segmentação do turismo é uma das ferramentas fundamentais e estratégica para identificar as atrações turísticas de uma localidade elencando suas potencialidades, aliando-se sempre com as expectativas do público alvo, os turistas. Pode-se compreender então, que a segmentação de mercado consiste na identificação dos diferentes grupos de consumidores e suas necessidades, que possibilitam oferecer um tipo de turismo específico a grupos específicos (Azevedo, Martins, Pizzinato \& Farah, 2012).

Essa especificidade, ligada ao turismo náutico, aliada ainda ao turismo de eventos, mais precisamente aos eventos esportivos náuticos, vem se apresentando como uma alternativa ao desenvolvimento da atividade na cidade de Itajaí (SC). Sua entrada neste segmento foi marcada pela edição da Volvo Ocean Race (VOR) em 2011-2012, a única parada da América Latina da maior regata de volta ao mundo por equipe. Com a VOR, a cidade de Itajaí entrou para a rota dos eventos náuticos internacionais, sediando novamente o evento em 2014-2015. Em 2017-
2018 a cidade sediou mais uma edição da VOR, que teve seu início no dia 22 de outubro de 2017 em Alicante na Espanha (Volvo Ocean Race, 2016). O evento possui repercussão internacional, sendo posicionada pelos seus realizadores como a Fórmula 1 dos mares.

Considerando todas as etapas da VOR, este se enquadra como o segundo evento esportivo mundial que mais recebeu visitante. Em sua penúltima edição concluída (2014/2015) recebeu 2.399.865 visitantes (Prefeitura Municipal de Itajaí, 2016). Conforme suas características pode-se considerar que o evento reúne atributos que permitem enquadrá-lo na classe de megaevento, uma vez que segundo Roche (1994, p. 19), megaevento é "um acontecimento de curta duração, com resultados permanentes nas cidades e/ou países que o sediam e está associado à criação de infra-estruturais e facilidades para o evento". Além disso, a VOR é um evento de grande importância a nível internacional, se enquadrando na definição de mega evento (Jago \& Shaw, 1998) e atendendo a critério mencionado por Getz (2005), por apresentar volume de pessoas superior a 1 milhão de visitantes.

Já a etapa brasileira de 2014/2015, a Itajaí Stopover,que recebeu um total de 320 mil visitantes na Vila da Regata (Prefeitura Municipal de Itajaí, 2016), reúne elementos que permitem configurá-la na classe de grande evento. Ritchie (1984) define esta classe de evento como: "importante uma vez que eventos recorrentes de duração limitada, desenvolvidos principalmente para aumentar a consciência, recurso e rentabilidade de um destino turístico, em curto prazo ou em longo prazo" (p.2). Tais eventos con- 
tam com o seu sucesso na singularidade, o estado ou o significado oportunos para criar interesse e atrair a atenção. Se enquadrando, assim, basicamente na proposta do Itajaí Stopover, que é divulgar e promover mundialmente as potencialidades turísticas do município de Itajaí, da região e de Santa Catarina, pretende atrair um significativo número de visitantes, que deve superar as edições passadas.

Lohmann e Netto (2008) e Barbosa (2013) relatam que os eventos são de suma importância para o desenvolvimento turístico, tanto os que ocorrem uma única vez, quanto os que se repetem com certa frequência, pois constituem parte da estratégia e da promoção e divulgação de marketing dos destinos. Politize (2015) e Pascoal e Gustavo (2017) mencionam que o país que recebe grandes eventos esportivos garante, mesmo que por um tempo limitado, uma grande atenção internacional, atraindo um fluxo maior de turistas e tornando-se mais conhecido no exterior.

Em se tratando do segmento de turismo náutico, Cardoso (2012) salienta sua importância e, a característica deste em não utilizar a embarcação como sendo apenas um meio de transporte, mas utilizá-la como demanda turística, agregando-lhe valor, tornando um patrimônio cultural, simbólico, natural e uma fonte para novos produtos turísticos do segmento náutico.

No entanto, sabe-se que os grandes eventos promovem trocas econômicas, políticas e culturais entre nações, e as relações que deles resultam, podem ser pacíficas ou conflituosas (Uvinha, Chan, Man \& Marafa, 2018). Deste modo, os eventos desportivos são importantes, tanto para o participante, quanto para a região que está sediando o evento, dando notoriedade e reconhecimento e contribuindo para o desenvolvimento da região, porém também podendo implicar em impactos depreciativos (Pappas, 2017). Porém, como sugere Jackson (2008), pouco se sabe sobre os impactos de eventos nas cidades que são sediados. Considera-se, neste sentido, que há a necessidade do planejamento turístico gerado por megaeventos, para que se possa causar o mínimo de impacto sob os moradores (Uvinha et al., 2018).

Quando se discutem esses impactos na ótica de quem os percebe, estes podem assumir diferenças tanto positivas quanto negativas (Saayman \& Slabbert, 2004, Kim \& Petrick, 2005). Dentro deste enfoque, há os impactos originados pela visita de turistas na região, assim como, pela movimentação da sociedade local, que em virtude dos eventos, segundo Mathieson e Wall (1982), ocasionam quatro tipos de impactos: econômico, cultural, social e ambiental.

Vale salientar que Garbacz (2013) e Kirkup e Sutherland (2017) ressaltam que os fatores de impactos culturais e sociais podem ser tratados conjuntamente com relação aos impactos que o turismo de eventos traz para a cidade. De igual forma, Dall'Agnol (2012) alude sobre como estes impactos podem trabalhar de forma dual, sendo necessário analisar a viabilidade em cada sociedade.

Porém, passado a efervescência do momento da realização das edições passadas, e diante da perspectiva de sediar novamente mais uma etapa do evento VOR, uma análise dos impactos na comunidade local se fez necessária. Alinhado a este propósito, definiu-se como objetivo do presente estudo 
analisar a percepção dos residentes da cidade de Itajaí (SC), após a realização do Itajaí Stopover, em relação aos impactos econômicos, socioculturais e ambientais gerados pela VOR. Especificamente avaliaram-se os impactos da VOR em Itajaí, percepcionados pela comunidade local (residentes), e posteriormente classificou-se, por meio da correlação o perfil dos residentes, as percepções positivas e negativas que se distinguem conforme segmentos investigados.

Conforme esses objetivos, o presente trabalho caracterizou-se como descritivo, de natureza quantitativa com método de abordagem do tipo survey. A população investigada foi composta por residentes da cidadesede de Itajaí (SC), com idade entre 20 e 69 anos, representada por uma amostra não probabilística de 484 respondentes.

Para fins de delimitação, define-se a priori que quando se analise as opiniões do residente no âmbito do evento, não é uníssono os julgamentos que se fazem, pois os interesses podem ser diferentes, assim como as percepções sobre os acontecimentos que o cercam (Lin, 2013). Essa diferença ocorre, principalmente porque diante de estímulos, o comportamento ou ação do indivíduo é afetado pela maneira como ele seleciona, organiza e interpreta as informações recebidas ou a absorção das sensações, ou seja, depende da sua percepção, afetada tanto por estímulos físicos, condições internas individuais e a relação destes com o ambiente (Solomon, 2016, Kotler \& Keller, 2012).

A seguir são discutidos temas pertinentes ao estudo, como o turismo náutico e os eventos esportivos náuticos, seguido pela discussão dos impactos dessas atividades em relação aos residentes. Apresenta-se em se- guida o delineamento metodológico da parte empírica, que precede a apresentação dos resultados e as considerações finais.

\section{TURISMO NÁUTICO E OS EVENTOS NÁU- TICOS ESPORTIVOS}

A atividade náutica se dá por meio de todas as atividades de navegação desenvolvidas sobre embarcações, águas paradas ou correntes, sejam elas fluviais, lacustres, marítimas ou até mesmo oceânicas. E quando esta atividade de navegação possui um cunho turístico, pode ser chamada de turismo náutico (Brasil, 2006).

Nessa conjuntura, pode-se definir o turismo náutico como sendo um conjunto de relações humanas, decorrentes de viagens com duração inferior a um ano, na qual sua motivação principal está na realização de atividades náuticas recreativas ou esportivas realizadas em locais como grandes lagos, rios ou mar aberto (Silveira \& Zibetti, 2015).

Dentre as diferentes possibilidades do receptivo turístico que proporcionam o crescimento das cidades, pode-se destacar o turismo náutico, que é mantido pela atividade de lazer, está ligada a atividades aquáticas em litorais, rios, lagoas, e se realizam por meio de pequenas embarcações até grandes navios (Hedlicka, Magalhães, Gallizia \& Guedes, 2005, Brasil, 2010).

Nas últimas décadas, o Brasil se manteve à margem das rotas de navegação de miIhares de turistas e velejadores que passeiam com seus barcos pelo mundo, devido as licenças de permanência do barco em águas nacionais e o visto do turista/proprietário da embarcação, situação que começou a mudar a partir de setembro de 2006. Como conse- 
qüência desta ação, a cada ano vem crescendo o número de barcos estrangeiros a circularem por águas brasileiras (Lima, 2009).

A análise do turismo do setor náutico nacional, apresentada por Loureiro (2004), mostrava que não é aproveitado todo o potencial existente. Essa situação também é descrita por Netto e Ansarah (2009) e Banuth (2010), que observaram que do ponto de vista da dimensão do país, o turismo náutico ainda é pouco explorado.

O turismo em questão movimenta miIhões, economicamente falando, e favorecem outros segmentos, como o turismo ecológico, o de aventura, o de natureza, bem como agrega valor à arquitetura, à gastronomia e à cultura local (Lima, 2009). Contudo, como as outras tipologias de turismo, o turismo náutico requer uma infra-estrutura básica de atendimento ao turista e suas embarcações, como os portos, atracadores, marinas e garagens náuticas (Reader, 2008, Brasil, 2010).

É possível caracterizar dois principais tipos no segmento do turismo náutico: o Turismo Náutico de Cruzeiro e de Recreio e Esporte (Brasil, 2010). No Turismo Náutico de Cruzeiro, a embarcação destaca-se como o próprio atrativo motivador do deslocamento e a turista procura aproveitar ao máximo as experiências internas do navio. Apesar disto, também é capaz de gerar forte impacto nas cidades e regiões onde os navios programam suas escalas. Já o Turismo Náutico de Recreio e de Esporte, tem como principal objetivo do turista a participação em eventos esportivos ligados à náutica. Algumas dessas pessoas programam seu calendário de maneira a via- jar para os locais e participarem de eventos/competições nacionais e internacionais.

Assume-se diante das argumentações apresentadas, que o turismo náutico, assim como na sua modalidade de turismo náutico de recreio e de esporte, pode estar ligado a eventos esportivos. Estes eventos são importantes para os que participam, mas são também muito importantes para a região e instituição que os desenvolve. Contribuindo com notoriedade e reconhecimento enquanto eventos de sucesso, e assim gerando impactos econômicos positivos para a localidade onde se estabelece.

Além da dimensão que o turismo náutico pode ter, em sua interface, ele pode abranger diversos tipos de eventos, sendo um deles o segmento de negócios e eventos. Os eventos nacionais quando bem elaborados e encaminhados, com intuito de atrair a atenção da mídia e do público interno, trazem a possibilidade de quebrar paradigmas como o de que a náutica é acessível apenas para uma classe restrita de pessoas e de alto poder aquisitivo. Informações bem contextualizadas passadas para a mídia e para o público podem atrair um número maior de curiosos e ampliar o leque de clientes dispostos a se envolver com o segmento (Brasil, 2010).

Os eventos desportivos têm como principal produto turístico o esporte, com o objetivo de deslocar turistas de suas regiões de origem para vivenciar ou assistir as mais distintas modalidades de esportes, podendo estes ser os núcleos esportivos tradicionais com calendários fixo de eventos ou a núcleos que eventualmente sediam olimpíadas, competições e torneios (Beni, 2003). 


\section{IMPACTOS DAS ATIVIDADES DE EVENTOS ESPORTIVOS}

Segundo Murphy (1985), o turismo é uma indústria que usa a comunidade como recurso para seu desenvolvimento, vende-a como um produto, e neste processo afeta as vidas dos moradores locais. Deste modo, Goeldner, Ritchie e Mclntosh (2002) relatam que a atividade turística nas comunidades locais e a geração de produtos e serviços para os visitantes, determinam transformações em suas estruturas nos âmbitos econômico, sociocultural e ambiental. Assim, os impactos decorrentes e seus desdobramentos positivos e negativos, nas localidades e regiões afetadas por esta atividade, se apresentam como matéria de investigação para a academia.

Santana (1997) diz que a atividade turística tem uma forte repercussão sobre as variáveis econômicas quantitativas (rendimento, emprego) e qualitativas (nível de vida, bem-estar) das regiões e países onde atua, sendo, portanto importante valorizar os seus aspectos positivos para a contribuição do desenvolvimento dos países e destinos turísticos. Njoroge, Atieno, Nascimento e Vieira (2017), assim como Santana (1997) já relata, mencionam que os impactos que geram a atividade turística sobre as economias de muitos países e regiões, têm sido um dos aspectos mais estudados na investigação na área do turismo.

Moreira e Silva (2007) expõem que, para atender os residentes de uma sociedade, deve-se compreender os principais componentes e ideias dos processos estratégicos para as cidades, com vista à elaboração de um diagnóstico de pontos fortes, pontos fracos, oportunidades e ameaças de modo a traçar objetivos tangíveis que se congratulem em um aumento da atratividade da cidade.

Os resultados do estudo de Cardona (2014) vêm de encontro com Moreira e Silva (2007), pois remetem a importância de se investigar o papel do residente, não apenas na construção do espaço, mas também na sua participação como agente e detentor do direito a ter seus anseios promovidos pelo marketing de cidades, ou por outros projetos e ações que a cidade possa produzir.

Dentre as atividades turísticas, têmse os eventos esportivos, apresentados atualmente em pequeno, médio e grande porte. Estes trazem resultados importantes para a economia, principalmente no que diz respeito a investimentos nas condições de infraestrutura, geração de empregos diretos e indiretos, geração de renda, atração de investimentos públicos e privados. Além disso, todos os megaeventos sediados no país merecem grande atenção, pois a cidade passa a ser reconhecida como sendo a sede de determinado evento noticiado (Zuba, 2009, Proni, Faustino \& Silva, 2014, Paiva, 2015).

Quando se estudam eventos, palavras como legados e impactos surgem como conceitos intensamente estudados. Tavares (2007) com o intuito de diferenciá-las, coloca que os legados estão atrelados à ideia de longo prazo, com ações permanentes, têm início no presente e que, se planejados adequadamente, podem ser positivos e benéficos, enquanto os impactos têm o caráter mais imediatista, com menor duração.

Geralmente, os impactos são mais frequentemente considerados como consequência a um efeito adverso, enquanto o termo legado é mais frequentemente usado 
ao apresentar efeitos positivos (Romano, Vico, Silva \& Uvinha, 2015). No entanto, os legados dependem da área a ser analisada para serem considerados positivos, negativos ou um pouco dos dois (Owen, 2005).

A reflexão de Pace, Hardt e Figueiredo (2015) aludem que o grande legado de megaeventos esportivos pode não estar ligado aos resultados dos jogos em si, mas a outros benefícios que chegam até à população. Nestes casos, os grandes eventos podem ser um importante gatilho para melhorar a qualidade de vida da população, proveniente das meIhorias de infra-estrutura nas mais diversas áreas, como o transporte, segurança, habitação e educação, entre outros. Seus efeitos, inclusive para o turismo, podem se transformar em um benefício que perdura para além do tempo de duração do evento. Nessa linha de raciocínio, autores como Santos (2000), Rodrigues, Dacosta, Pinto e Terra (2008) e Reis (2008) destacam que os megaeventos são como grandes catalisadores e facilitadores de investimentos, no intuito de não ter um fim em si mesmo.

A geração de empregos e o conseqüente incremento significativo no consumo da economia do país sede, proporcionado pela realização de megaeventos esportivos, é outro fator atraente e bastante discutido pelos autores. O aumento do turismo oriundo de grandes eventos possibilita a geração de empregos diretos e indiretos em hotéis, restaurantes e outras áreas ligadas diretamente à recepção de estrangeiros (Souza, Miranda, Moreira, \&Tabak, 2015).

Embora pouco se saiba sobre os impactos de eventos em comunidades de acoIhimento, considera-se que a participação em megaeventos cria muitos impactos positivos e negativos (Jackson, 2008), porém, segundo Twynham e Johnson (2004) e Garbacz (2013), as percepções sobre os impactos podem aparecer nos períodos que precedem o evento, durante e após o evento.

Entre os principais agentes interessados na realização de um evento estão os residentes da cidade que o sedia. $O$ sucesso de um evento desse porte não é possível sem que os residentes sejam ouvidos, contudo, é preciso atentar para a mutualidade de sua opinião. Pessoas podem ter opiniões diferentes sobre o evento de acordo com os acontecimentos que estiverem influenciando sua percepção no momento. Existem múltiplas vozes dentro da comunidade local que possuem opiniões e interesses diferentes, além disso, grupos demográficos específicos da mesma comunidade podem ter opiniões distintas se possuírem atitudes diferentes sobre o mesmo assunto (Lin, 2013).

Nesta concepção um número crescente de estudos tem sido realizado sobre a percepção dos residentes de megaeventos esportivos. A maioria empregou métodos de investigação transversais, porém sem que as percepções dos residentes fossem acompanhadas durante um período de tempo significativo (Kim, Gursoy \& Lee, 2006). Desta forma, as atitudes e apoio dos moradores que poderiam variar ao longo do tempo, bem como as razões para essa variação, poderiam colaborar com novas políticas, assim como os organizadores de eventos desportivos entendessem melhor a percepção dos residentes das cidades-sede.

Muller (2012) em seu estudo sobre os residentes de Sochi, sede dos Jogos Olímpi- 
cos de Inverno de 2014, inferiu que os impactos positivos são aqueles que mais promovem o apoio popular, fortalecendo o apoio ao evento, ao contrário dos impactos negativos que tendem a colaborar para a insatisfação, resultando em formas de oposição. O mesmo percebeu Gursoy e Kendall (2006) nos Jogos Olímpicos de Inverno de 2002 em Salt Lake City (EUA), em que para eles o apoio popular depende mais dos benefícios do que os custos percebidos.

Sendo assim, por mais que um evento seja custoso, o governo deve focar para que o legado do megaevento gere benefícios de longo prazo para a vida dos residentes. Por sua vez, as percepções dos impactos socioculturais dos megaeventos, como a Copa do Mundo da FIFA, serão diferentes de uma comunidade sede para outra, assim como seus perfis sócio demográficos (Watt, 2004).

\section{METODOLOGIA DE PESQUISA}

No que tange aos objetivos, o presente trabalho caracteriza-se como uma pesquisa descritiva, de abordagem quantitativa, uma vez que se pretende analisar a percepção dos residentes da cidade de Itajaí (SC), em uma perspectiva após a realização da Itajaí Stopover, considerando os impactos econômicos, socioculturais e ambientais gerados pela VOR.

A pesquisa descritiva está alinhada principalmente com base nos dados oriundos do método Survey, que tem por finalidade a descrição de fenômenos ou relacionar variáveis, possibilitando a sintetização das informações coletadas de forma clara e concisa e salientando os principais aspectos, sem distorções (Santos, 1999, Barbosa \& Milone,
2006, Barrow, 2008).

Neste caso, em específico, procurouse descrever as características sócio demográficas de sua população, bem como, das opiniões concernentes às variáveis utilizadas para medir a percepção dos residentes quanto aos impactos. Isso vai ao encontro da caracterização quantitativa quanto à natureza dos dados, que tende a enfatizar o raciocínio indutivo, as regras da lógica e os atributos mensuráveis da experiência humana.

O método survey busca informação diretamente com um grupo de interesse a respeito dos dados que se deseja obter. Trata-se de um procedimento útil, especialmente em pesquisas exploratórias e descritivas (Santos, 1999). Já o método e-survey ou Eletronic Survey, Jansen, Corley e Jansen, (2007) o caracterizam como meio de obtenção de dados, entendendo-se por pesquisa on-line, sendo um questionário auto administrável em que o público-alvo pode concluílo on-line. Geralmente são criadas como formulário da Web com um banco de dados para armazenar as respostas e possuem um software estatístico para ajudar nas análises.

A necessidade de informações cada vez mais rápidas e valiosas exige o desenvolvimento de novos métodos para coleta e tratamento de dados pela internet de modo que as técnicas tradicionais, combinadas a novas ferramentas, possam proporcionar o dinamismo, a eficiência e a confiabilidade. Assim, para potencializar a obtenção de uma amostra que atendesse a necessidade deste estudo, a aplicação ocorreu combinando o canal pessoal e a internet.

A presente pesquisa concentrou seu público alvo nos residentes da cidade-sede de Itajaí (SC), especificamente entre aqueles 
com idade entre 20 e 69 anos, com o objetivo de mensurar os impactos promovidos pela VOR. As delimitações das idades definidas consideram a possibilidade de enquadramento às faixas etárias utilizadas pelo Instituto Brasileiro de Geografia e Estatística (IBGE), bem como a garantia de entrevistar indivíduos que possuíam 18 anos ou mais.

Entre os tipos de amostra possíveis, a utilizada neste estudo caracteriza-se como não probabilística, cuja acessibilidade constitui-se como critério de seleção. Para Creswell (2010), pesquisa não probabilística é aquela que a seleção dos elementos da população para compor a amostra depende em parte do julgamento do pesquisador ou do entrevistador no campo. A amostra final foi composta por 484 casos válidos, com a participação de 226 homens (46,7\%) e 258 mulheres (53,3\%).

Para o presente estudo, os bairros do município de Itajaí foram agrupados de acordo com a proximidade com o bairro onde a Vila da Regata da VOR em Itajaí é montada. A criação das cinco regiões $(R)$ considerou a Região 1 (R1 - Centro da cidade), como aquela em que o evento ocorre, a R2 (São João, Vila Operária, São João e Fazenda) compreendendo os bairros que possuem limítrofe ao bairro centro. Na R3 (Dom Bosco, Ressacada, São Vicente, São Judas, Cabeçudas, e Barra do Rio) incluem-se os que fazem limítrofe com os bairros da R2, a R3 (Cordeiros, Praia Brava e Cidade Nova) e R5 (bairros mais distantes: Murta, Itaipava, Brilhante, Km 12, Espinheiros, Arraial dos Cunhas, São Roque, Baia, Salseiros, Rio do Meio, Paciência, Limoeiro e Campeche). O intuito foi de permitir avaliar se a proximidade pode ser um fator de influência nos resultados.

A coleta de dados foi efetuada no mês de agosto de 2017 por meio de questionário estruturado, contendo questões que se associam direta e indiretamente as dimensões (econômica, sociocultural, ambiental) analisadas nesta pesquisa. As variáveis utilizadas foram baseadas no estudo de Garbacz (2013), que avaliou a percepção dos residentes moradores de Varsóvia (Polônia) após a Eurocopa de 2012.

A distribuição do link Survey (questionário) foi realizada por meio do Facebook com uma plataforma patrocinada restrita aos residentes de Itajaí, listas de transmissão do Whatsapp e por e-mail.

Os dados resultantes dos questionários foram digitalizados em formato de banco de dados e as análises conduzidas com auxílio do programa estatístico SPSS (Statistical Packagefor the Social Science), versão 22. Posteriormente, as variáveis foram correlacionadas, e consequentemente tratadas de forma a trazer respostas e compreensão quanto à percepção dos residentes de Itajaí frente ao turismo e ao evento, objeto deste estudo.

Também foi feita uma análise utilizando o teste ANOVA, também chamado de análise da variância, que se trata de uma técnica estatística utilizada para estudar as diferenças entre as médias de dois ou mais estratos investigados (Barbosa \& Milone, 2006). A análise de variância compara médias de diferentes grupos para verificar se estes possuem médias iguais ou não, permitindo que vários grupos sejam comparados ao mesmo tempo. 


\section{RESULTADOS DA PESQUISA}

Nesta seção são apresentados e discutidos os resultados obtidos na fase de campo da pesquisa. Inicialmente apresentase o perfil da amostra dos entrevistados e, em seguida, a avaliação da percepção dos residentes do município de Itajaí quanto às dimensões dos impactos oriundos da VOR, a correlação do perfil dos residentes e as percepções das dimensões investigadas.

\subsection{Perfil da amostra e envolvimento com a etapa Itajaí Stopover}

No que se refere ao gênero, a maioria da população amostrada pertence ao feminino (53,3\%), enquanto $46,7 \%$ é o percentual de pessoas do sexo masculino. O que já era esperado, uma vez que dados de senso populacional do IBGE (2017) demonstram que a população feminina é maior que a masculina no município. Além da identificação do gênero populacional, foram observadas a escolaridade e a faixa etária, conforme a tabela 1.

Tabela 1 -Perfil dos entrevistados $(n=484)$

\begin{tabular}{|c|c|c|}
\hline Gênero & Frequência & Percentagem \\
\hline Feminino & 258 & $53.3 \%$ \\
\hline Masculino & 226 & $46.7 \%$ \\
\hline Total & 484 & $100 \%$ \\
\hline Idade & Frequência & Percentagem \\
\hline 20 a 29 & 123 & $25.4 \%$ \\
\hline 30 a 39 & 169 & $34.9 \%$ \\
\hline 30 a 49 & 92 & $19,0 \%$ \\
\hline 50 a 59 & 66 & $13.6 \%$ \\
\hline 60 a 69 & 34 & $7.0 \%$ \\
\hline Total & 484 & $100 \%$ \\
\hline Escolaridade & Frequência & Percentagem \\
\hline Ensino fundamental incompleto & 10 & $2.1 \%$ \\
\hline Fundamental completo & 19 & $3.9 \%$ \\
\hline Médio completo & 144 & $28.9 \%$ \\
\hline Superior completo & 153 & $31.6 \%$ \\
\hline Pós-graduação completa & 158 & $32.6 \%$ \\
\hline Total & 484 & $100 \%$ \\
\hline Renda familiar & Frequência & Percentagem \\
\hline Até 3 salários min. & 100 & $20,7 \%$ \\
\hline 3 a 5 salários min. & 134 & $27,7 \%$ \\
\hline 5 a 8 salários min. & 128 & $26,4 \%$ \\
\hline Acima de 8 salários min. & 117 & $24,2 \%$ \\
\hline $\mathrm{NI}$ & 5 & $1,0 \%$ \\
\hline Total & 484 & $100 \%$ \\
\hline
\end{tabular}

Fonte: Pesquisa direta 2017

Os 484 respondentes investigados permitiram representatividade nas diferentes faixas etárias, porém concentrando-se entre 30 a 39 anos $(34,9 \%)$ e 20 a 29 anos
$(25,4 \%)$. Apenas $6 \%$ da amostra apresentou escolaridade no nível de ensino fundamental completo ou incompleto.Outros $28,9 \%$ com ensino médio e $64,2 \%$, com no mínimo gra- 
duação completa. Também se obteve uma amostra bem distribuída nas diferentes faixas de renda apresentadas, com leve destaque para os de 3 a 5 salários mínimos $(27,7 \%)$ e de 5 a 8 salários mínimos (26,4\%).

A respeito do conhecimento e participação como público no evento, observou-se que a população tem amplo conhecimento do mesmo (96,5\%), e ao menos uma prova da etapa do evento foi assistida por $65,5 \%$ da amostra. Destacando que 66,5\% demonstraram interesse em assistir novas edições da VOR.

\subsection{Avaliação da percepção dos residentes do município de Itajaí quanto às dimen- sões dos impactos oriundos da VOR}

Nesta seção, são discutidos os resultados referentes à percepção dos residentes do município de Itajaí em relação aos impactos, pós-evento, nas dimensões econômica, sociocultural e ambiental gerados pela VOR.

No que se refere aos impactos ocasionados à dimensão econômica, diversos estudos apontam para um impacto positivo para a cidade local em relação à realização de megaeventos. Mas, de acordo com Oliveira e Salazar (2011), a literatura internacional questiona, frente aos diversos pontos relacionados a tais estudos. Isso devido ao fato de serem pesquisas encomendadas ou realizadas por pessoas ou instituições que apresentam ligação ou envolvimentos diretos com a defesa, a organização e a realização dos megaeventos esportivos, como é o caso das instituições esportivas internacionais (FIFA, COI) e as diversas esferas governamentais.

Do mesmo modo, Proni, Faustino e Silva (2014) apontam para uma situação com troversa observada em relação à Copa do Mundo de 2006 e 2010, realizadas na Alemanha e África do Sul, respectivamente, quando o assunto é o legado econômico para a cidade-sede do evento. Segundo os autores, os benefícios esperados na economia dos países que sediaram as Copas não se confirmaram isso, quando comparados aos valores obtidos em levantamentos posteriores aos campeonatos. Nesta linha, Barros (2016) relata que os estádios construídos ou reformados na copa do Brasil, também são poucos viáveis economicamente no pós-copa.

Contudo, tal realidade mostrou-se divergente, pelo menos quando considera a percepção dos residentes do município de Itajaí (SC), em relação à realização da VOR. A tabela 2 mostra as variáveis analisadas correspondentes aos impactos na dimensão econômica proporcionado pela a VOR ao município de Itajaí (SC). De acordo com os resultados obtidos pela presente pesquisa, foi observado a partir da média 3,99, que os respondentes concordaram que a VOR atraiu mais investimento para a cidade.

De modo geral, é possível observar que os residentes entrevistados apresentaram um nível de concordância superior ao nível de discordância, exceto para o questionamento Q36, que se refere a melhoria da renda familiar proporcionada pelo o evento VOR. Nesta variável da dimensão econômica, identificou-se um grau superior de discordância, atingindo a menor média entre as demais, com 2,35 pontos e desvio padrão de 1,04. Resultado próximo a este também ocorreu na variável Q15, com uma pequena vantagem para o nível de concordância quando questionado se o evento é responsável por aumentar os preços dos produtos e serviços, 
resultando em uma média de 3,12 pontos, segunda menor da dimensão econômica. A diferença é que esta é uma variável negativa e a anterior positiva.

A variável Q14, que trata do efeito VOR para a promoção da cidade como destino turístico, bem como a variável Q13, relacionada a promoção do comércio local foram as que obtiveram as melhores avaliações nesta dimensão, com médias de 4,32 e 4,05 pontos respectivamente, e desvios padrões de 0,79 e 0,83, os menores da dimensão.

A questão Q36 (Melhora diretamente minha renda familiar?) apresentou uma percentagem maior para as pessoas que discordaram que o evento traz melhorias para renda familiar. A explicação deste fato pode estar ligada ao nível de envolvimento dos entrevistados com a realização do evento, pois, $21,7 \%$ dos entrevistados não tiveram nível de envolvimento com o evento, e $68,8 \%$ foram visitantes/participantes do evento.

Desse modo, pode-se constatar, que a nível de percepção dos residentes do município de Itajaí (SC), a VOR tem gerado mais impactos positivos quanto à dimensão econômica, principalmente no que se refere as variáveis mais abrangentes, ou seja, para a cidade sede como um todo. Porém, quando o impacto trata de variáveis mais individuais, essa percepção mais positiva não acontece.

Estudos como os de Diaz e Gutiérrez (2010) e de Cardona (2014), relatam que a percepção das pessoas em relação aos impactos sociais ocasionados por eventos turísticos, tende a ser considerada negativa, quando comparados aos impactos econômi- cos, o mesmo sendo observado para os impactos nas dimensões socioculturais e ambiental.No entanto, para o município de Itajaí (SC), observa-se uma situação diferente da elencada acima, já que em sua grande maioria, foi percebida como positiva em relação aos benefícios introduzidos pela a VOR (Tabela 2).

Desse modo, foi possível observar grande concentração das pessoas entrevistadas em nível de concordância e ou concordância plena com a afirmação de que a realização da VOR ofereceu a cidade de Itajaí (SC) mais visibilidade nacional e internacional, apresentando média de 4,32 e desvio padrão de 0,69, assim como, proporcionou um aumento nos meios recreativos e de lazer, mesmo que em menor proporção. Tal melhoria foi confirmada por meio da média de 3,37 e desvio padrão de 0,91.

De acordo com Llopis-Goig (2012) existe uma grande diversidade de termos e de significados quanto aos impactos que costumam ser associados a dimensão social dos megaeventos esportivos. Tais impactos, geralmente, se remetem a sentimento de orguIho, reforço da identidade coletiva, melhora da qualidade de vida, aumento da interação social e da prática esportiva, prestígio e reconhecimento internacional.Ainda segundo o autor, os pontos negativos, em contrapartida, também relacionados a aspectos sociais, são destacados como: aumento da insegurança, suspensão do modo de vida local, intensificação do tráfego, infrações aos direitos humanos, exacerbação do nacionalismo e da xenofobia e impactos ambientais. 
Tabela 2 - Variáveis correspondentes aos fatores econômicos, sociocultural e ambiental proporcionado pela a VOR ao município de Itajaí (SC)

\begin{tabular}{|c|c|c|}
\hline DIMENSÃO ECONÔMICA & $\begin{array}{c}\text { Média } \\
(\dot{x})\end{array}$ & $\begin{array}{l}\text { D. P. } \\
\text { (S) }\end{array}$ \\
\hline Q11 - O evento atrai mais investimentos para cidade? & 3,99 & 0,87 \\
\hline Q12 - Traz maiores oportunidades de emprego? & 3,76 & 0,95 \\
\hline Q13 - Promove o comércio local? & 4,05 & 0,83 \\
\hline Q14 - Promove a cidade como destino turístico? & 4,32 & 0,79 \\
\hline Q15 - É responsável por aumentar os preços dos produtos e serviços? & 3,12 & 0,96 \\
\hline $\begin{array}{l}\text { Q16 - Proporciona desenvolvimento da infra-estrutura da cidade e outros serviços } \\
\text { que podem ser utilizados posteriormente ao evento pelos residentes? }\end{array}$ & 3,55 & 1,03 \\
\hline Q36 - Melhora diretamente minha renda familiar? & 2,35 & 1,04 \\
\hline DIMENSÃO SOCIOCULTURAL & $\begin{array}{c}\text { Média } \\
(\dot{x})\end{array}$ & $\begin{array}{l}\text { D. P. } \\
\text { (S) }\end{array}$ \\
\hline Q17 - Melhora infra-estrutura pública (acessos e estradas da cidade de Itajaí)? & 3.11 & 1.08 \\
\hline Q18 - Aumenta os meios recreativos e de lazer? & 3,73 & 0,91 \\
\hline Q19 - A cidade de Itajaí fica superlotada durante o evento? & 3,01 & 0,96 \\
\hline Q20 - Aumenta a tensão social (aparecimento ou aumento de grupos desfavorecidos) & 2,53 & 0,84 \\
\hline Q21 - Coloca os moradores locais predispostos a muitos acidentes? & 2,14 & 0,74 \\
\hline Q22 - Perturba e tira a paz dos moradores de Itajaí? & 1,95 & 0,70 \\
\hline Q23 - A cidade fica perigosa durante o evento? & 2,01 & 0,73 \\
\hline Q24 - Aumenta o congestionamento e tráfego urbano? & 2,93 & 0,98 \\
\hline Q25 - A cidade tem visibilidade nacional e internacional? & 4,32 & 0,69 \\
\hline Q26 - Causa perda de identidade e cultura local? & 2,02 & 0,84 \\
\hline Q27 - Destrói o patrimônio histórico/cultural? & 1,90 & 0,72 \\
\hline Q31 - A cidade fica mais alegre e mais unida? & 3,85 & 0,94 \\
\hline Q32 - Traz orgulho aos moradores da cidade? & 4,16 & 0,84 \\
\hline Q33 - Os impactos positivos do evento superam os impactos negativos? & 3,90 & 0,92 \\
\hline Q34 - A cidade deve sediar outros eventos? & 4,33 & 0,74 \\
\hline Q35 - É bom para a cidade o fluxo do turismo? & 4,35 & 0,71 \\
\hline DIMENSÃO AMBIENTAL & $\begin{array}{c}\text { Média } \\
(\dot{x})\end{array}$ & $\begin{array}{l}\text { D. P. } \\
\text { (S) }\end{array}$ \\
\hline Q24 - Aumenta o congestionamento e tráfego urbano? & 2,93 & 0,98 \\
\hline Q28 - Aumenta a sensibilização e conscientização ambiental da comunidade local? & 3.47 & 0.97 \\
\hline Q29 - Aumenta a poluição ambiental (ruídos, solos, água). & 2.40 & 0.79 \\
\hline
\end{tabular}

Fonte: Pesquisa direta 2017

Dessa forma, observa-se que, nem sempre, um evento turístico acarreta apenas impactos positivos para a sociedade. No entanto, quando interrogados a respeito se os impactos positivos do evento superam os impactos negativos (Q33), foi observado que a percepção do desenvolvimento de megaeventos oferece maiores benefícios para so- ciedade em geral, com média de 3,90 e desvio padrão de 0,92. Segundo Santana (1997), os impactos socioculturais resultam, portanto, das relações sociais que se estabelecem entre os residentes e os visitantes. A intensidade e forma desses impactos variam dependendo do tipo do visitante, das diferenças culturais entre os grupos, do grau de 
adaptação dos visitantes e dos costumes locais.

Llopis-Goig (2012) destaca que os pontos negativos gerados por megaeventos na dimensão social ou sociocultural são: aumento da insegurança, suspensão do modo de vida local, intensificação do tráfego, infrações aos direitos humanos, exacerbação do nacionalismo e da xenofobia e impactos ambientais. Neste caso, apenas os questionamentos Q19 e Q24 apresentaram um equilíbrio entre as opiniões, com média de 3,01 e desvio padrão de 0,96 para a Q19 e média de 2,89 e desvio padrão de 0,98 para a Q24, mostrando que existe uma divergência de resultados quando comparados ao relatado por Llopis-Goig (2012).

Situação semelhante foi encontrada no que diz respeito a questão Q23. De acordo com os resultados obtidos pela presente pesquisa, observa-se que a cidade de Itajaí não é considerada mais perigosa durante a realização da VOR, uma vez que os residentes entrevistados demostram discordar dessa afirmação, com média de 2,01 e 0,73 de desvio padrão. Vale salientar que quando se trata da realização de megaeventos, existe uma maior preocupação, por parte de governantes, em relação à segurança dos cidadãos. Mas como o estudo não foi realizado durante o evento, tal fato não pode ser considerado, o que pode significar que, realmente, o evento não acarreta no aumento da criminalidade.

Silveira (2016) aplicou um método de análise de percepção dos impactos ocasionados por eventos turísticos semelhante ao utilizado na presente pesquisa. Segundo os resultados obtidos pela autora, o evento turístico, na percepção dos residentes de Balneá- rio Camboriú (SC), tende a acarretar a perda de identidade e cultura local, uma vez que os respondentes tendem a concordar com o questionamento. Tal resultado foi divergente ao encontrado na presente pesquisa. Segundo os residentes do município de Itajaí (SC), a VOR não proporciona a perda da identidade e cultura local, já que tendem a discordar do questionamento Q26, com média de 2,02 pontos. Tal abordagem, apesar da distinção entre as cidades estudadas, serve para mostrar que existe uma subjetividade em relação à experiência vivenciada por cada pessoa, corroborando para a ideia de que o que pode ser positivo para um, pode não ser para outro.

Nesse contexto, Silvestre (2009) e Chain e Swart (2010) abordam que os impactos se fazem intrínsecos a realização dos eventos e que merecem destaque aqueles decorrentes do aumento da auto-estima e do orgulho cívico da população local, tendo em vista ainda, a possibilidade de fortalecimento da coesão social e da construção de uma identidade nacional.

Partindo contra a ideia da perda da identidade cultural em consequência da realização de megaeventos, de acordo com Wacker e Wacker (2008) alguns autores relatam que a realização de megaeventos esportivos pode agregar memória cultural, deixando legados desde que contextualizado com o momento histórico. Exemplo disso são os Jogos Olímpicos de Atenas em 2004 e da Copa do Mundo de Futebol em 2006 na Alemanha.

A atividade turística ocasionada pela realização de grandes eventos gera também impactos consideráveis sobre o meio ambiente (Besen \& Moretto-neto, 2005). O exer 
cício da atividade turística provoca impactos ambientais positivos e negativos, envolvendo o ambiente natural, o ambiente transformado e o ambiente sociocultural. No entanto, o ambiente natural é mais vulnerável aos impactos ambientais negativos do turismo (Fandé \& Pereira, 2014).

A variável 24 também abordada na dimensão sociocultural, possui, de acordo com autores como Barczak e Duarte (2012) um viés ambiental, uma vez que carros parados em congestionamentos poluem muito mais do que movimento, pois os congestionamentos geram um relevante impacto ambiental devido a emissão de gases na atmosfera, a exemplo do CO2. Porém, a percepção do residente de Itajaí, respondente da pesquisa, assume uma posição de indiferença quanto ao aumento de tráfego urbano provocado pela VOR, já que a média alcançou 2,93 pontos, com desvio padrão de 0,98.

Ainda segundo os residentes, a realização do evento turístico esportivo VOR contribui para a conscientização ambiental da comunidade local, porém, em nível pouco acima de uma situação indiferente ( $\dot{x}=3.47$ / $S=0.97)$. Observa-se também, em posição contrária, que os residentes discordam ( $\dot{\mathbf{x}}=$ 2.40 / $S=0.79$ ) da afirmação de que a VOR contribui para a poluição do ambiente (Q29). Vale salientar, apesar da origem da certificação, que o município de Itajaí recebeu o troféu de melhor programa de sustentabilidade "Certificado Volvo de Conscientização Ambiental 2011/2012", em reconhecimento aos projetos de sustentabilidade desenvolvi dos na Itajaí Stopover, no período de 04 a 22 de abril (Prefeitura Municipal de Itajaí, 2016).

Isso mostra que de fato o município realizou um planejamento e se preparou ade- quadamente para receber o evento turístico esportivo, principalmente quando comparado as demais cidades em outros países, que também foram sedes da regata.

Tratando-se da atividade turística como um todo, resultados divergentes foram encontrados por Silveira (2016) e Fandé e Pereira (2014), que observaram que a percepção dos residentes acarreta impactos ambientais negativos, quanto à degradação ambiental.

\subsection{Correlação do perfil dos residentes e as percepções das dimensões investigadas}

Nesta seção são apresentados os resultados referentes à correlação entre as dimensões econômica, sociocultural e ambiental. Essa correlação se deu por meio da análise de variância (ANOVA) procurando identificar percepções significativamente distintas em relação à VOR, quando verificados os resultados segundo a faixa etária, gênero, renda familiar, escolaridade e região de moradia. Os resultados são apresentados apenas para as variáveis que apresentaram nível de significância estatística $<0,05$. Tradicionalmente, o valor de corte para rejeitar a hipótese nula é de 0,05 , o que significa que, quando não há nenhuma diferença, um valor tão extremo para a estatística de teste é esperado em menos de $5 \%$ das vezes (Ferreira \& Patino, 2015).

$O$ teste ANOVA foi aplicado inicialmente para as médias conforme faixa etária (Tabela 3). A variável Q15 (É responsável por aumentar os preços dos produtos) apresentou significância entre as médias muito baixa, sendo de 0,000001. Foi possível perceber que pessoas com faixa etária entre 20 a 29 anos apresentaram visão menos positiva que 
as demais faixas etárias ( $\dot{x}=3,37)$, com maior nível de concordância que a VOR impactou no aumento de preços dos produtos e serviços. Ainda em relação à dimensão econômica, existe diferença significativa $(0,016)$ na percepção dos residentes quanto ao ques- tionamento Q36 (Melhora diretamente minha renda familiar?). Nesta variável, mesmo com médias inferiores a 3 (neutro), percebese que pessoas com a faixa etária entre 60 a 69 anos apresentam uma atitude menos negativa em relação às demais faixas etárias.

Tabela 3 - Relação das dimensões com a faixa etária

\begin{tabular}{cccccccc}
\hline DIMENSÃO & Variável & 20 a 29 & 30 a 39 & 40 a 49 & 50 a 59 & 60 a 69 & Sig \\
\hline \multirow{2}{*}{ ECONÔMICA } & Q15 & 3,37 & 3,16 & 3,00 & 2,97 & 2,62 & 0,000 \\
& Q36 & 2,12 & 2,41 & 2,45 & 2,30 & 2,74 & 0,016 \\
SOCIOCULTURAL & Q21 & 2,27 & 2,20 & 1,93 & 2,11 & 2,00 & 0,010 \\
& Q24 & 3,14 & 2,93 & 2,76 & 2,86 & 2,74 & 0,041 \\
AMBIENTAL & Q29 & 2,58 & 2,49 & 2,27 & 2,21 & 2,00 & 0,001 \\
\hline
\end{tabular}

Fonte: Pesquisa direta 2017

Na dimensão sociocultural, a variável Q24 (Aumenta o congestionamento e tráfego urbano?) apresentou uma diferença entre as médias com significâncias de 0,041 em relação às faixas etárias. Mostrando que pessoas com faixa etária entre 20 a 29 anos apresentam uma percepção com maior nível de concordância $(\dot{x}=3,14)$ do que as outras faixas etárias estudadas.

Essa variável (Q24) também pertence a dimensão ambiental, que analisado conjuntamente à variável Q29(Aumenta a poluição ambiental - ruídos, solos, água), demonstra temdência de maior sensibilidade desse grupo etário às questões do meio ambiente e possível impacto da VOR neste sentido. Contudo, ressalta-se que nesta última variável, apesar da significância de 0,001, a média de
2,58 pontos assume posição entre a discordância e a neutralidade.

A aplicação do teste ANOVA para as dimensões e a variável gênero possibilitaram identificar diferença significativa na percepção de homens e mulheres apenas na dimensão sociocultural, ou seja, para todas as demais variáveis e dimensões ambos os gêneros percebem da mesma forma os impactos gerados pela VOR (Tabela 4). Nesta, observase que, em geral, os respondentes femininos apresentam um nível de discordância levemente menos intenso do que os respondentes do gênero masculino. Como essas variáveis são representadas por aspectos negativos, essa menor discordância posiciona as mulheres respondentes como mais críticas aos aspectos apresentados.

Tabela 4 - Relação das dimensões com gênero

\begin{tabular}{ccccc}
\hline DIMENSÃO & Variável & Feminino & Masculino & Sig \\
\hline & Q22 & 2,02 & 1,87 & 0,014 \\
DIMENSÃO SOCIO- & Q23 & 2,08 & 1,93 & 0,026 \\
CULTURAL & Q26 & 2,13 & 1,89 & 0,002 \\
& Q27 & 1,96 & 1,83 & 0,042 \\
\hline
\end{tabular}

Fonte: Pesquisa direta 2017 
Apesar de na escala o valor 2 (dois) representar uma percepção de discordância quanto à VOR destruir o patrimônio histórico/cultural (Q27), a média entre as respondentes femininas $(1,96)$ é superior a alcançada pelos respondentes masculinos, com diferença estatística de significância 0,042.Já em relação a variável Q22, foi encontrado significância estatística entre as médias de 0,0014 . Desse modo, percebe-se também uma visão mais discordante para pessoas do gênero masculino, quando questionadas se o evento perturba e tira paz dos moradores de Itajaí, apresentando média de 1,87. Essas situações também são semelhantes nas variáveis Q23 (A cidade fica perigosa durante o evento?) e Q26 (Causa perda de identidade e cultura local?), com significâncias estatísticas de 0,026 e 0,002 respectivamente. As médias entre as mulheres foram de 2,08 e 2,13, enquanto entre os homens 1,93 e 1,89.

Na ANOVA para a relação dimensões e renda familiar (Tabela 5), pode-se observar que para a dimensão econômica, houve uma significância de 0,025 entre as rendas familiares, evidenciando assim uma maior predominância de pessoas entrevistadas com renda familiar entre 3 a 5 salários mínimos (média de 3,26) que demonstram maior concordância com a variável Q15 (É responsável por aumentar os preços dos produtos e serviços?).

Tabela 5 -Relação das dimensões com renda familiar

\begin{tabular}{ccccccc}
\hline DIMENSÃO & Variável & $\begin{array}{c}\text { Até 3 sa- } \\
\text { lários } \\
\text { min. }\end{array}$ & $\begin{array}{c}3 \text { a } 5 \text { salá- } \\
\text { rios min. }\end{array}$ & $\begin{array}{c}5 \text { a } 8 \text { sa- } \\
\text { lários } \\
\text { min. }\end{array}$ & $\begin{array}{c}\text { Acima de } \\
8 \text { salários } \\
\text { min. }\end{array}$ & Sig \\
\hline $\begin{array}{c}\text { DIMENSÃO } \\
\text { ECONÔMICA }\end{array}$ & Q15 & 3,23 & 3,26 & 3,05 & 2,93 & 0,025 \\
\hline Q30 & 4,01 & 4,19 & 4,22 & 4,32 & 0,029 \\
DIMENSÃO & Q33 & 3,68 & 3,81 & 3,91 & 4,21 & 0,000 \\
SOCIOCULTURAL & Q34 & 4,19 & 4,34 & 4,30 & 4,50 & 0,020 \\
& Q20 & 2,76 & 2,52 & 2,50 & 2,35 & 0,005 \\
Q21 & 2,33 & 2,16 & 2,12 & 1,97 & 0,004 \\
AMBIENTAL & Q23 & 2,20 & 2,00 & 1,95 & 1,91 & 0,021 \\
\hline
\end{tabular}

Fonte: Pesquisa direta 2017

Já na dimensão social, é possível observar uma média superior para a variável Q34 (A cidade deve sediar outros eventos?), apresentando significância de 0,020 e média de 4,50 para pessoas com salário acima de 8 (oito) salários. A variável Q29 (aumenta a poluição ambiental?) apresentou significância de 0,00001, com menor nível de discordância entre aqueles com até 3 salários mínimos.
Porém, destaca-se que de maneira geral, percebe-se que as médias foram baixas, próximo a 2 (dois).

O teste de média por meio da ANOVA para a relação da dimensão sociocultural com o nível de escolaridade resultou em diferenças estatísticas com significância de 0,014para a variável Q19 (A cidade de Itajaí fica superlotada durante o evento?), a partir de uma maior média $(3,80)$ para pessoas com 
nível fundamental incompleto. Vale ressaltar que na amostra analisada, apenas 10 pessoas possuem nível de escolaridade fundamental incompleto (Tabela 6). Situação semelhante foi observada para a variável Q20 (Aumenta a tensão social), que apresentou uma significância de 0,022 entre as médias, sendo que a maior média foi para pessoas também com nível de escolaridade fundamental incompleto.

Tabela 6 - Relação da dimensão com o nível de escolaridade.

\begin{tabular}{cccccccc}
\hline DIMENSÃO & Variável & $\begin{array}{c}\text { Fundamental } \\
\text { incompleto }\end{array}$ & $\begin{array}{c}\text { Fundamental } \\
\text { completo }\end{array}$ & $\begin{array}{c}\text { Médio } \\
\text { completo }\end{array}$ & $\begin{array}{c}\text { Pós-graduação } \\
\text { completa }\end{array}$ & $\begin{array}{c}\text { Superior } \\
\text { completo }\end{array}$ & Sig \\
\hline DIMENSÃO & Q19 & 3,80 & 3,42 & 3,04 & 2,98 & 2,91 & 0,014 \\
SOCIOCULTURA & Q20 & 3,30 & 2,63 & 2,59 & 2,45 & 2,48 & 0,022 \\
\hline
\end{tabular}

Fonte: Pesquisa direta 2017

Foi desenvolvida uma análise das possíveis variações de impactos gerados pela VOR em relação aos bairros de residências dos respondentes. Desse modo, foi feita uma classificação dos bairros da cidade, sendo eles divididos em 5 regiões, considerando a região mais próxima do evento (R1), que se refere exatamente ao local onde está sedia- do a Vila da Regata e, a mais distante (R5). A tabela 7 mostra a quantidade de pessoas entrevistadas e percentagem de acordo com as regiões, na qual é possível perceber que a Região R3, R5 e R2, foram as que apresentaram as maiores percentagens, sendo $27,7 \%$, $27,5 \%$ e $21,7 \%$, respectivamente

Tabela 7 - Quantidade de residentes entrevistadas e percentagem por região

\begin{tabular}{ccc}
\hline Região de residência & Número & $\%$ \\
\hline R1 & 68 & $14,0 \%$ \\
R2 & 105 & $21,7 \%$ \\
R3 & 134 & $27,7 \%$ \\
R4 & 44 & $9,1 \%$ \\
R5 & 133 & $27,5 \%$ \\
Total & 484 & $100,0 \%$ \\
\hline
\end{tabular}

Fonte: Pesquisa direta 2017

A aplicação da análise de variância (ANOVA) não identificou médias diferentes que pudessem representar significância estatística < que 0,05. O resultado representa que, independentemente da proximidade da residência do local onde ocorrem as principais atividades do evento, a percepção quanto aos impactos não difere, seja estas percepções positivas, neutras ou negativas.

\section{CONSIDERAÇÕES FINAIS}

A Volvo Ocean Race vem se consolidando no calendário de eventos de Itajaí e região, devido em sua maioria aos vários investimentos destinados à sua realização, e que, de acordo com os resultados apresentados pelos organizadores, Prefeitura Municipal de Itajaí e pelos veículos de imprensa local, se 
justifica mediante a importância que o evento adquiriu.

Nesse contexto, as notícias existentes até a realização deste trabalho relataram que o evento, de uma maneira geral, se fez benéfico para o desenvolvimento da cidade de Itajaí. Entretanto, ainda não era possível compreender qual a percepção dos residentes em relação ao evento, sendo esses os maiores afetados por sua realização.

Os impactos econômicos em sua grande maioria são rotineiramente positivos, principalmente no que diz respeito à indústria do turismo, ao comércio e também no legado deixado para a infraestrutura da cidade. Contudo, em um contexto geral, os residentes não são beneficiados com um aumento na renda familiar. Dessa forma, pode-se concluir que as melhorias nas dimensões econômicas, mesmo não imediatas, são positivas para o município sede.

As análises da dimensão sociocultural são de suma importância para perceber o quão os residentes são diretos e indiretamente impactados pelas ações governamentais e privadas que envolvem a realização da VOR. E, nesse caso, foi possível perceber que os impactos positivos superam os negativos, principalmente nas dimensões socais e econômica. Isso pôde ser visto quanto a questão da segurança da cidade e também a temática referente à paz proporcionada pelo evento, que segundo os residentes, não deixa a cidade mais perigosa e também não perturba a paz.

Com base nas análises da dimensão ambiental, foi possível perceber que a VOR gera moderada conscientização ambiental nos residentes, uma vez que o evento em si tem em seus preceitos a valorização da natu- reza, e isso indiretamente é repassado para os residentes envolvidos diretamente ou não no evento. No entanto, observa-se um número elevado de residentes com opiniões neutras quanto ao quesito ambiental.

O desenvolvimento metodológico desta pesquisa ainda permitiu visualizar por meio do teste ANOVA que as mulheres residentes de Itajaí apresentaram uma percepção mais positiva em um contexto sociocultural em relação ao sexo masculino. Ao mesmo tempo que pessoas com a faixa etária entre 60 a 69 anos também apresentaram uma atitude mais positiva em relação às demais faixas etárias quanto aos impactos econômicos.

Em relação ao nível de escolaridade, foi possível observar que os residentes com nível de escolaridade fundamental incompleto apresentaram percepção menos negativa em relação aos questionamentos da dimensão sociocultural (aumento de tensão na população e superlotação da cidade durante o evento).

Em um contexto geral, foi possível perceber por meio da realização deste trabaIho que a maioria dos residentes têm uma percepção positiva da VOR, acreditando que o evento e as circunstâncias que o concerne trazem benefícios para a cidade e, conseqüentemente, para a população em geral.

Considerando que os resultados apresentados neste trabalho tenham ocorrido embasados nas percepções dos residentes da área de estudo, pesquisas mais aprofundada no sentido de avaliar a relação custo-benefício da VOR em Itajaí (SC) se fazem necessárias para complementar este panorama acerca de sua viabilidade, uma vez que são investidos vários recursos no desenvolvimen- 
to de situações que visem as melhores condições para o desenvolvimento logístico do evento.

A natureza não probabilística da amostra utilizada nesta investigação deve ser considerada como limitação do estudo, já que os resultados alcançados são restritos às percepções dos participantes da pesquisa, não podendo ser inferidos como representativos da população de estudo.

Estudos futuros poderão ser aplicados nas novas edições, possibilitando comparações longitudinais sobre a percepção dos impactos gerados pelo evento. Nestas novas edições, abordagens analisando expectativa na fase do pré-evento, bem como percepções dos residentes durante o evento, também poderão contribuir para uma análise de possíveis influências do momento em que o levantamento é realizado. Além disso, também no âmbito dos stakeholders locais, sugere-se a aplicação da pesquisa com outros públicos, caso dos empresários, envolvidos ou não no trade turístico local.

\section{REFERÊNCIAS}

Azevedo, M. S., Martins, C. B., Pizzinato, K. N., Farah, O. E. (2012). Segmentação no setor turístico: O turista IGBT de São Paulo. Santa Maria: Rev. Adm. UFSM, 5 (3), 493-506.

Banuth, E. (2010). Turismo em áreas de represa: caracterização e evolução no município de Arealva (SP). 2010. 141 f. Dissertação (Mestrado em Hospitalidade) - Universidade Anhembi Morumbi. São Paulo.

Barbosa, D. L. R., Milone, G. (2006). Estatística Aplicada ao Turismo no Brasil: Observatório de Inovação do Turismo. Rio de Janeiro: Senac Nacional.

Barbosa, F. F. (2005). O turismo como fator de de senvolvimento local e/ou regional. Caminhos da Geografia, 10(14), 108.

Barbosa, F. S. (2013). Planejamento estratégico para eventos: um estudo de caso das estratégias de marketing utilizadas para a Oktoberfest de Santa Cruz do Sul/RS. Revista de Cultura e Turismo, 14, 87-104.

Barczak, R., Duarte, F. (2012).Impactos ambientais da mobilidade urbana:cinco categorias de medidas mitigadoras. Brazilian Journal of Urban Management, 4 (1), 13-32.

Barros, T. S. (2016). Análise de Viabilidade Econômica dos Estádios da Copa do Mundo FIFA 2014. Revista Gestão Organizacional, 9 (1), 43-65.

Barros, M. O., Granero, A. E. (2010). A Promoção de Eventos como alternativa de desenvolvimento turístico na região de Franca. XI Encontro de Pesquisadores. Unifacef, França.

Barrow, M. (2008). Estatística para Economia, Contabilidade e Administração. São Paulo: Ática. Beni, M. C. (2003). Análise estrutural do Turismo. São Paulo: Senac.

Besen, F., Moretto-neto, L. (2005). Turismo de Eventos Esportivos a avaliação da contribuição para economia da cadeia produtiva turística: um estudo de caso do Ironman Brasil 2005. XII SIMPEP. Bauru.

Brasil, (2006). Ministério do Turismo. Turismo Náutico Orientações Básicas. ed. Brasília: Ministério do Turismo.

Brasil, (2010). Ministério do Turismo. Turismo Náutico: orientações básicas. 3. ed. Brasília: Ministério do Turismo.

Cardona, J. R. (2014). Tipos de oferta turística y actitudes de los residentes: el caso de Ibiza. $R e$ vista Brasileira de Pesquisa em Turismo. 8 (1), 322. DOI: https://doi.org/10.7784/rbtur.v8i1.704

Cardoso, T. de F. (2012). O turismo náutico em Balneário Camboriú (SC) e os efeitos da sazonalidade. 2012. $62 \mathrm{f}$ Monografia (Bacharel em Turismo) - Universidade Estadual do Centro-Oeste 
do Paraná, Irati.

Chain, D., Swart, K. (2010). Residents' Perceptions of the 2010 FIFA World Cup: A Case Study of a Suburb in Cape Town, South Africa. Alternation, 17 (2), 146-172.

Creswell, J. W. (2010). Projeto de pesquisa: métodos qualitativo, quantitativo e misto. 3. ed. Porto Alegre: SAGE.

Dall'agnol, S. (2012). Impactos do turismo x comunidade local. SEMINTUR - Anais do VII Seminário de Pesquisa em Turismo do Mercosul. Turismo e Paisagem: relação complexa. 16 e 17 de novembro de 2012. Universidade de Caxias do Sul. Mestrado em Turismo. Caxias do Sul (RS), Brasil.

Díaz, R., Gutiérrz, D. (2010). La actituddel residente enel destino turístico de Tenerife: evaluación y tendencia. PASOS: Revista de Turismo y Patrimônio Cultural, 8 (4), 431-444. DOI: https://doi.org/10.25145/i.pasos.2010.08.039

Fandé, M. B., Pereira, V. F. G. C. (2014). Impactos ambientais do turismo: um estudo sobre a percepção de moradores e turistas no Município de Paraty-RJ. Revista Eletrônica em Gestão, Educação e Tecnologia Ambiental - REGET, 18 (3), 1170-1178.

Ferreira, J. C., Patino, C. M. (2015). O que realmente significa o valor-p? Jornal Brasileiro de Pneumologia. 2015, 41(5), 485-485. Disponível em: $\quad<$ http://dx.doi.org/10.1590/S180637132015000000215> Acessado em: 17 de Agosto de 2017.

Garbacz, J. (2013). Evaluation of the Impact of a Mega-Sporting Event: Perception of Warsaw Residents towards UEFA Euro 2012. Department Msc Degree in Economics, Markets And Public Policies. Universidade do Minho, Braga, Portugal.

Getz, D. (2005). Event Management end Event Tourism. 2aed. New York, Cognizant Communication Corporation.

Goeldner, C. R., Ritchie, J. R. B., Mcintosh, R. W. (2002), Turismo: Princípios, Práticas e Filosofias.
Tradução de Roberto Cataldo Costa (8 a ed.). São Paulo: Bookman.

Gursoy, D, Kendall, K. W. (2006). Hosting mega events modeling locals' support. Pergamon: Annals of Tourism Research, Washington, 33 (3), 603-623. DOI: https://doi.org/10.1016/i.annals.2006.01.005

Hedlicka, H, Magalhães, H. R,Gallizia, K. R., Guedes, L. M. (2005). Panorama do turismo náutico de lazer. In Trigo, L. G., Panoesso Neto, A., Aldrigui, M.. Análises regionais e globais do turismo. São Paulo: Roca.

IBGE - Instituto Brasileiro de Geografia e Estatísticas. Cidades. (2017). Site de internet. Disponível em: <https://cidades.ibge.gov.br/brasil/sc/itajai/panorama>. Acessadoem: 27 Setembro de 2017.

Jackson, L. A. (2008). Residents' Perceptions of the Impacts of Special Event Tourism. Journal of Place Management and Development, 1 (3), 240255.

DOI:

https://doi.org/10.1108/17538330810911244

Jago, L. K. e Shaw, R. N. (1998). A Conceptual and differential framework. Festival Management and Event Tourism. 5 (1/2), 21-32. DOI: https://doi.org/10.3727/106527098792186775

Jansen, K. J., Corley K. G., Jansen, B. J. (2007). ESurvey Methodology. In: Reynolds R. A., Woods's, R. \& Baker, J. D. (2007) Handbook of research on electronic surveys and measurements. Idea Group Inc. DOI: https://doi.org/10.4018/978-159140-792-8.ch001

Kim, H.J., Gursoy, D., Lee, S.B. (2006). The impact os the 2002 World Cup on South Korea: comparisons of pre-and post games. Tourism Management, $27 \quad$ (1), 86-96. DOI: https://doi.org/10.1016/j.tourman.2004.07.010

Kim, S. S., Petrick, J. F. (2005). Residents' perceptions on impacts of the FIFA 2002 World Cup: the case of Seoul as a host city. Tourism Management, $26 \quad$ (1), 25-38. DOI: https://doi.org/10.1016/i.tourman.2003.09.013 
Kirkup, N., Sutherland, M. (2017) Exploring the relationships between motivation, attachment and loyalty within sport event tourism. Current Is sues in Tourism, 20 (1). 7-14. DOI: https://doi.org/10.1080/13683500.2015.1046819

Kotler, P., Keller, K, L. (2012). Administração de marketing. 14 ed. São Paulo: Pearson Education do Brasil.

Lima, R. (2009). Turismo náutico sustentável: um diferencial competitivo. In: Netto, A., Ansarah, M. (Org.). Segmentação do mercado turístico: estudos, produtos e perspectivas. Barueri: Manole.

Lin, Y. (2013). A Critical Review of Social Impacts of Mega-events. The International Journal of Sport and Society, 3 (3), 57-64. DOI: https://doi.org/10.18848/21527857/CGP/v03i03/59412

Llopis-goig, R. (2012). Repercusiones y efectossociales de los megaeventos. Acotaciones teóricas y evidencia empírica. In: LLOPIS-GOIG, Ramón (Ed.). Mega eventos deportivos: Perspectivas científicas y estudios de caso. Barcelona: UOC, 97-115.

Lohmann, G., Netto, P. A.(2008). Teoria do turismo: conceitos, modelos e sistemas. São Paulo: Aleph.

Loureiro, L. V. (2004). Desenvolvimento da atividade náutica no Estado da Bahiao centro náutico da Bahia. 2004. 135 f. Dissertação (Mestrado em Administração) - Universidade Federal da Bahia, Salvador.

Mathieson, A., Wall, G. (1982). Tourism - economic, physical and social impacts, Longman, London.

Moreira, J. R. M., Silva, M. J. (2007). Marketing das Cidades Estudo da Identidade: o caso da cidade da Covilhã. Conocimiento, innovación y emprendedores: camino al futuro. Universidade Beira Interior, 2007. Disponível em: <https://dialnet.unirioja.es/descarga/articulo/2233140.pdf> Acesso em: 10 novembro de 2016.

Muller, M. (2012). Popular perception of urban transformation through mega events: understanding support for the 2014 Winter Olympics in Sochi. Environment and Planning C: Government and Policy, 30 (4), p. 693 - 711. DOI: https://doi.org/10.1068/c11185r

Murphy, P. (1985). Tourism: A community approach, Routledge, London.

Netto, P. A., Ansarah, M.G.R. (2009). Segmentação do mercado turístico: estudos, produtos e perspectivas. Barueri: Manole.

Njoroge, J. M., Atieno, L., Nascimento, D., Vieira D. (2017). Sports Tourism and Perceived Socioeconomic Impact in Kenya: the case of Machakos County. Tourismand Hospitality Management, 23 (2), 195-217. DOI: https://doi.org/10.20867/thm.23.2.9

Oliveira, M., Salazar, A. (2011). Os impactos do turismo: o caso da viagem medieval de Santa Maria da Feira. In: International Conference on Tourism \& Managment Studies: 1, Algarve. p 744-765. 2011. Disponível em:<www.tmstudies.net/index.php/ectms/article/download/240/351>.

Acessoem: 18 de maio de 2017.

Owen, J. (2005). Estimating the cost and benefit of hosting Olympic Games: what can Beijing expect from its 2008 Games? The Industrial Geographer, 3 (1), 1-18.

Pace, T. H., Hardt, L. P. A., Figueiredo, F. C. (2015). Sorting mega-events and tourism: bibliometric relation ships in academia. Business and Management Review, 4 (12).

Pappas, N. (2017). Pre- and Postevaluation of Residents' Participation and Support of the 2012 London Olympics. Event Management, 21 (6), 747-770.

DOI: https://doi.org/10.3727/152599517X1507304723725 $\underline{0}$

Pascoal, J., Gustavo, N. (2017). Turismo de eventos desportivos como alavanca estratégica para o desenvolvimento e o posicionamento de um destino turístico: caso dos $\mathrm{X}$ jogos africanos Maputo 2011 (Moçambique). Revista Turismo \& Desenvolvimento, 1 (27/28), 986-1001. 
Paiva, R. A. (2015). Eventos e Megaeventos: ócio e o negócio no turismo. Revista Brasileira de Pesquisa em Turismo. 9 (3), 479-499. DOI: https://doi.org/10.7784/rbtur.v9i3.890

Politize. (2015). Copa do Mundo e Jogos Olímpicos: valeu a pena? Site de internet. Disponível em: <http://www.politize.com.br/copa-domundo-e-jogos-olimpicos-valeu-a-pena/20135>. Acesso em: 15 de janeiro de 2018.

Prefeitura Municipal de Itajaí (2016). Secretaria de Turismo. Site de internet. Disponível em: $<$ http://www.itajai.sc.gov.br $>$. Acesso em: 4 de agosto de 2016.

Proni, M., Faustino, R., Silva, L. (2014). Impactos Econômicos de Megaeventos Esportivos. Belo Horizonte: Casa da Educação Física.

Reader, S. (2008). Desenvolvimento Urbano em Sedes de Megaeventos Esportivos. In: Dacosta, L., Corrêa, D., Rizutti, E., Villano, B., Miragaya, A. Eds. Legados de megaeventos esportivos. Brasília: Ministério do Esporte, p. 201-209.

Reis, A.C. (2008). Megaeventos e turismo: uma breve revisão. In Rodrigues, R.P., Da Costa, L, Pinto, L. M., Terra, R. Legados de megaeventos esportivos. Ministério do Esporte. DF, Brasil.

Ritchie, J. R. B. (1994). Assessing the impact of hallmark events. Journal of Travel Research, 23(1), 2-11. DOI: https://doi.org/10.1177/004728758402300101

Roche, M. (1994). Megaevents and urban policy. In: Annalsof Tourism Research. 21, 1994, Nova York. Anais... Nova York: Pergamon Press. DOI: https://doi.org/10.1016/0160-7383(94)90002-7.

Rodrigues, R. P., Dacosta, L., Pinto, L. M. \& Terra, R. (2008). Legados de megaeventos esportivos. Ministério do Esporte. DF, Brasil.

Romano, F. S, Vico, R. P., Silva, A. C., Uvinha, R. R. (2015). Megaeventos esportivos: Uma reflexão sobre os legados da UEFA Eurocopa. Revista Podium, Sport, Leisure and Tourism Review, 4 (3), 153-168. DOI: https://doi.org/10.5585/podium.v4i3.141
Saayman, M., Slabbert, E. (2004). A profile of tourists visiting the Kruger National Park. Koedoe, 47 (1), 1-8. DOI: https://doi.org/10.4102/koedoe.v47i1.74

Santana, A. (1997). Antropología y Turismo, Barcelona, Editorial Ariel.

Santos, A. R. (1999). Metodologia científica: a construção do conhecimento. Rio de Janeiro: DP\&A.

Santos, D. S. dos, Wanderley, C. B. (2009). Impactos quantitativos do turismo nas finanças municipais. $6^{\circ}$ Seminário de Economia de Belo Horizonte. Belo Horizonte.

Santos, M. P. (2000). Expo'98 ao Euro 2004: notas para o estudo do impacto de grandes eventos no turismo regional. Educação e Comunicação. (4). 22-47.

Silveira, D. M. P. (2016). Atitudes dos residentes quanto ao desenvolvimento do turismo: uma análise do destino turístico Balneário Camboriú/SC. 2016. 119 f. Dissertação (mestrado em Turismo e Hotelaria) - Universidade do Vale do Itajaí, Balneário Camboriú.

Silveira, M. A. T. da, Zibetti, R. A. (2015). O turismo náutico como vetor de desenvolvimento turístico da região hidrográfica do Paraguai: desafios e Oportunidades. $9^{\circ}$ Seminário de Transporte e Desenvolvimento Hidroviário Interior.

Silvestre, G. (2009). The Social Impacts of MegaEvents: Towards a Framework. Esporte e Sociedade, ano 4, 10.

Solomon, M. R. (2016). O comportamento do consumidor: comprando, possuindo e sendo. 11. ed. Porto Alegre: Bookman.

Souza, P. R. P., Miranda, R. B., Moreira, T. B. S., Tabak, B. M. (2015). Impactos econômicos e investimentos setoriais da Copa de 2014 no Brasil. Revista Research Gate. junho 2015. Disponível em: <https://www.researchgate.net/publication/273891694_Impactos_economicos_e_investimentos_setori 
ais_da_Copa_de_2014_no_Brasil $>$. Acesso em: 25 de março de 2017.

Tavares, O. (2007). Instalações temporárias do Pan Rio 2007: possíveis legados. In: Rubio, K. (Org.). Megaeventos esportivos, legado e responsabilidade social. São Paulo: Casa do Psicólogo.

Twynam, D.G., Johnston, M. (2004). Changes in host community reactions to a special sporting event. Current Issues in Tourism, 7(3), 242-261. DOI: https://doi.org/10.1080/13683500408667981

Uvinha, R. R., Chan, C., Man, C. K., Marafa, L. F. (2018). Sport tourism: a comparative analysis of residents from Brazil and Hong Kong. Revista Brasileira de Pesquisa em Turismo, 12(1), 180-206. DOI: https://doi.org/10.7784/rbtur.v12i1.1374

VolvoOceanRace. (2016) Volvo Eu Rodo. Revista Eletrônica. Disponível em: $<$ http://www.volvo.com.br/corp/eu rodo/er108e/er108ebx.pdf>. Acessado em: 24 de abril de 2016.

Wacker, C., Wacker, M. F. N. (2008). A produção da memória nos jogos olímpicos de Atenas de 2004 e da Copa do mundo de Futebol 2006 na Alemanha. Legados de Megaeventos esportivos. Brasil. Ministério do Esporte, 417-420.

Watt, D. C. (2004). Gestão de Eventos em Lazer e Turismo. Porto Alegre: Bookman.

Zuba, T. de A. (2009). Rio de Janeiro: uma cidade de eventos. Revista Contemporânea, 12, 155166.

Zucco, F. D., Quadros, C. M. B., Schmitt, J. R., \& Fiuza, T. F. (2017). Imagem e Identidade Turísticas Relacionadas às Práticas e Bens Culturais Percebidas pelos Residentes: Perspectivas a Partir da Cidade de Blumenau, Santa Catarina, Brasil. Revista Brasileira de Pesquisa em Turismo, 11(2), 320-346.

https://doi.org/10.7784/rbtur.v11i2.1309

DOI:

Informações dos autores

\section{Josy Vieira}

Mestre em Administração pela Universidade do Vale do Itajaí - UNIVALI (2017). Especialista em Administração e Gestão de Pessoas pela Faculdade Avantis (2015) e Graduada em Administração com Ênfase em Marketing (2011) e em Turismo e Hotelaria (2007), ambos pela UNIVALI. Tem experiência profissional em planejamento, organização, controle e assessoria nas áreas de recursos humanos, financeiro, comercial, compras e marketing, no segmento de administração pública e privada.

ORCID: https://orcid.org/0000-0002-5871-727X

E-mail: josyvieiraitajai@gmail.com

\section{Carlos Marcelo Ardigó}

Doutor em Engenharia de Produção na Área de Concentração de Inteligência Organizacional pela Universidade Federal de Santa Catarina (UFSC) em 2013; Mestre em Administração pela UFSC (2002); Especialista em Marketing pela Universidade do Vale do Itajaí (UNIVALI) em 1996 e Graduado em Administração também pela UNIVALI (1993). Atualmente é professor do Programa de Mestrado Profissional em Administração (PMPGIL) e do Programa de Mestrado e Doutorado em Turismo e Hotelaria (PPGTH), ambos da UNIVALI. Leciona nos cursos de pós-graduação em nível de especialização da UNIVALI nos MBAs de Gestão Estratégica, de Marketing, de Finanças e de Pessoas, do MBA em Gestão Estratégica do Design, MBA em Marketing Criativo e MBA em Gestão Estratégica de Varejo e Vendas. É Professor e Coordenador do Curso de Graduação em Administração da UNIVALI, campus Balneário Camboriú.

ORCID: https://orcid.org/0000-0002-3374-2401

E-mail: marcelo.ardigo@univali.br

\section{Hans Peder Behling}

Doutor em Ciências da Linguagem (UNISUL/2013), Bolsista PDSE-CAPES (Université de Montréal/2012), Mestre em Ciências da Linguagem (UNISUL/2006), Especialista em Gestão Estratégica de Negócios (FURBINPG/2001), Bacharel em Comunicação Social - Publicidade e Propaganda (FURB/1999). Atua na UNIVALI (Universidade do Vale do Itajaí) como professor no PMPGIL (Programa de Mestrado Profissional em Administração - Gestão, Internacionalização e Logística), como coordenador e professor no Curso de Pós-Graduação em Marketing Criativo, e como coordenador e professor no Curso de Graduação em Publicidade e Propaganda. Experiência de mercado na área de Marketing, Comunicação, Publicidade e Propaganda. ORCID:http://orcid.org/0000-0003-0558-9304

E-mail: hanspeda@univali.br 